\title{
A Novel Synthesis Route of Mesoporous $\gamma$-Alumina from Polyoxohydroxide Aluminum
}

\author{
Felipe Módolo Segal ${ }^{a}$,Michelle Fidelis Correa ${ }^{b}$, Rebeca Bacani ${ }^{e}$, Bruna Castanheira, \\ Mario José Politid, Sergio Brochsztain ${ }^{c}$, Eduardo Rezende Triboni ${ }^{a *}$
}

\author{
${ }^{a}$ Departamento de Engenharia Química - DEQ, Escola de Engenharia de Lorena da Universidade de \\ São Paulo, Estrada Municipal do Campinho, s/n ${ }^{\circ}$, CEP 12.602-810, Lorena, SP, Brazil \\ ${ }^{b}$ Departamento de Ciências Exatas e da Terra, Universidade Federal de São Paulo - UNIFESP, Rua São \\ Nicolau, 210, CEP 09913030, Diadema, SP, Brazil \\ ${ }^{c}$ Centro de Engenharia, Modelagem e Ciências Sociais Aplicadas da Universidade Federal do ABC, \\ Santo André, SP, Brazil \\ ${ }^{d}$ Instituto de Química, Universidade de São Paulo, Av. Prof. Lineu Prestes, 748, CEP 05508900, São \\ Paulo, SP, Brazil \\ eDepartamento de Engenharia de Materiais - DEMAR, Escola de Engenharia de Lorena da \\ Universidade de São Paulo, Pólo Industrial, Gleba Al-6, s/n, CEP 12602-810, Lorena, SP, Brazil
}

Received: July 21, 2017; Revised: October 04, 2017; Accepted: November 10, 2017

\begin{abstract}
Mesoporous gamma-aluminas $\left(\gamma-\mathrm{Al}_{2} \mathrm{O}_{3}\right)$ were synthesized starting from an unusual precursor of polyoxohydroxide aluminum (POHA). This precursor was obtained from aluminum oxidation in alkaline water-ethanol solvent in the presence of d-glucose that induces the formation of a gel, which leads to the POAH powder after ethanolic treatment. Precipitated POHAs were calcined at different temperatures $\left(300,400,700\right.$ and $\left.900{ }^{\circ} \mathrm{C}\right)$ resulting in the metastable $\gamma-\mathrm{Al}_{2} \mathrm{O}_{3}$ phase. Whereas at 300 ${ }^{\circ} \mathrm{C}$ no $\gamma-\mathrm{Al}_{2} \mathrm{O}_{3}$ phase was formed, unexpectedly, mesoporous $\gamma-\mathrm{Al}_{2} \mathrm{O}_{3}$ was obtained at $400{ }^{\circ} \mathrm{C}$ having a high specific surface area $\left(282 \mathrm{~m}^{2} / \mathrm{g}\right)$ and a narrow pore size distribution. At higher temperatures, the aluminas had the expected decrease in surface area: $166 \mathrm{~m}^{2} / \mathrm{g}\left(700{ }^{\circ} \mathrm{C}\right)$ and $129 \mathrm{~m}^{2} / \mathrm{g}\left(900{ }^{\circ} \mathrm{C}\right)$, respectively. The structural change from POHA to alumina calcined at $400^{\circ} \mathrm{C}$ occurs directly without the need to isolate the hydroxide or oxyhydroxide aluminum precursors. Both POHA and transition aluminas were characterized by Fourier Transform Infrared spectroscopy (FTIR), X-ray diffraction (XRD), $\mathrm{N}_{2}$ sorption and Scanning Electron Microscopy (SEM). These findings show an alternative route to produce high standard aluminas.
\end{abstract}

Keywords: aluminum and d-glucose, EtOH- $\mathrm{H}_{2} \mathrm{O}$ alkaline medium, chemical preparation, mesoporous gamma- $\mathrm{Al}_{2} \mathrm{O}_{3}$.

\section{Introduction}

The control of morphology and crystallinity in materials is very important due to its close relationship between structure and function. Thus, the search for synthetic routes for obtaining new selected materials with the desired properties is aimed ${ }^{1-5}$.

Alumina compounds are known to present exceptional structural stabilities and quite large specific surface areas, one of the reasons why these compounds are widely used for catalysis and adsorption processes ${ }^{6-12}$. The narrow connection that exists between the structure of the starting material and that of the target can be exemplified in the preparation of several types of aluminas such as corundum $\left(\alpha-\mathrm{Al}_{2} \mathrm{O}_{3}\right)$ and several transition aluminas $\left(\mathrm{x}-, \mathrm{K}-, \gamma-, \delta-, \mathrm{e}-, \eta-\mathrm{Al}_{2} \mathrm{O}_{3}\right)$ commonly synthesized at different temperatures by calcination of their trihydroxide and oxyhydroxide precursors ${ }^{13-20}$. Renewed interest in a novel and facile synthesis methods of aluminum oxides using these precursors are thus envisaged.

*e-mail: tribonier@usp.br
$\gamma$-Alumina $\left(\gamma-\mathrm{Al}_{2} \mathrm{O}_{3}\right)$ is a very important transition alumina since it has acidic sites and it is widely used in the petrochemical industry ${ }^{21}$. This alumina is used as well as a catalyst scaffold allowing the dispersion of several active phases as metals and metallic oxides for important organic reactions and several advanced technological applications ${ }^{22-25,7,10,12}$. The main precursor for the synthesis of $\gamma$-alumina commonly used is the aluminum oxyhydroxide (Boehmite), $\gamma$-AlOOH. A peculiar characteristic observed in this process is that during the calcination the dehydration has been related as a topotactic reaction ${ }^{26}$. By other hands, Bayerite $\left(\beta-\mathrm{AlOH}_{3}\right)$ and Gibbsite $\left(\alpha-\mathrm{AlOH}_{3}\right)$ precursors could be used but the phase transformation pathway has different outcomes ${ }^{13,27-35}$.

Up to date literature highlights the effect of hydroxylated compounds directing the precipitation of aluminum hydroxide and as well on the alumina phase formation ${ }^{18,36-38}$. Obrenovic et al. investigated the precipitation of aluminum hydroxides from diluted Bayer's liquor in the presence and absence of d-glucose obtaining boehmite and bayerite phases, respectively. These starting compounds are then calcined for obtainment 
of mesoporous aluminas ${ }^{39}$. In these context in a previous work aluminum oxidation in alkaline alcohol-water 3:1 (v:v) yielded a paramagnetic organic-bayerite material. It was shown the need of this high ethanolic fraction to the precipitation of the bayerite ${ }^{40}$.

In this work, we present a novel method to obtain $\gamma$ $-\mathrm{Al}_{2} \mathrm{O}_{3}$ from polyoxohydroxide aluminum ion (POHA) precipitated with d-glucose as an inductor additive. The synthesis of POHA was carried out under ultrasonic condition to promote the oxidation of elemental aluminum in $\mathrm{KOH}$ ethanol-water with the addition of d-glucose. The POHA powders were calcined and a novel tandem reaction was taken into account to the transformation where the POHA ion changes straightforward to $\gamma-\mathrm{Al}_{2} \mathrm{O}_{3}$ without the need to obtain previously the trihydroxide or oxyhydroxide precursors. $\gamma-\mathrm{Al}_{2} \mathrm{O}_{3}$ was formed at the temperatures of 400, 700 and $900{ }^{\circ} \mathrm{C}$. Calcination at $400{ }^{\circ} \mathrm{C}$ resulted in $\gamma-\mathrm{Al}_{2} \mathrm{O}_{3}$ having a surface area of $282 \mathrm{~m}^{2} / \mathrm{g}$ and a narrow pore volume. These features highlight the importance of a synthetic method by simple precipitation, whereas in most current methods it is necessary to prepare the (pseudo-)boehmite or bayerite precursors.

\section{Experimental}

\subsection{POHA powder synthesis}

Aluminum powder (99.9\% Reagent) and ethanol (Mallinkrodt) were used as received. Water was doubly distilled and further purified via a Millipore Milli-Q system, others reagents were of the best available grade (Aldrich). The d-glucose was purchased from Merck and used without further purification.

Aluminum powder, $\mathrm{Al}(400 \mathrm{mg}), \mathrm{KOH}(1.5 \mathrm{~g})$ in 40 $\mathrm{mL}$ ethanol:water $3: 1(\mathrm{v}: \mathrm{v})$ ratio and $50.0 \mathrm{mg}$ d-glucose were added to an Erlenmeyer flask and the suspension was sonicated in an ultrasonic bath (output of $125 \mathrm{~W} / 20 \mathrm{KHz}$ ). After the total dissolution of the aluminum, it was verified the formation of two phases with a gel at the bottom of the flask. The gel was separated by decantation and 100 $\mathrm{mL}$ ethanol dropped stepwise under stirring, the resulting solid (1.5 g) was filtered out and thoroughly washed with water and ethanol and following dried in an oven at $70^{\circ} \mathrm{C}$. Resulting powders were calcined for 2 hours at 300, 400, 700 , and $900^{\circ} \mathrm{C}$, in a muffle furnace under air.

\subsection{POHA powder characterization}

XRD diffraction patterns of the samples were obtained on an X-Ray Diffractometer Rigaku Miniflex (30 kV/15 $\mathrm{mA})$, using a $\mathrm{Cu}$ tube, $\mathrm{K}_{\alpha}(\lambda=1.5418 \AA)$ with Ni filter. MDI Jade 6.5 software was used to access PDF database and indexing. The as-synthesized and calcined samples were also characterized by Fourier Transform Infrared Spectroscopy (FTIR) with a Bomen model MB 100 using KBr pellets in the range 4000 to $500 \mathrm{~cm}^{-1}$. The surface morphology was evaluated by scanning electron microscopy (SEM) using a Hitachi $3400 \mathrm{~N}$ instrument. Nitrogen adsorption/desorption isotherms were measured with a Quantachrome Nova $2200 \mathrm{e}$. The samples were pretreated by degassing at $55^{\circ} \mathrm{C}$ for 24 hours. The specific surface area was obtained using the Brunauer Emmett Teller (BET) method; the pore size distribution (PSD) was derived from the adsorption branches of the isotherms using the BJH method. The microporosity was estimated using the t-plot method.

\section{Results and Discussion}

\section{1 FTIR spectroscopy}

Figure 1 shows the FTIR spectra of POHA, before and after calcination. In Fig. 1(a) the peaks at 3434 and 1642 $\mathrm{cm}^{-1}$ can be assigned to vibrational (bending and stretching, respectively) modes of the hydroxyl group of adsorbed water.

The overlapped band centered at $620 \mathrm{~cm}^{-1}$ presenting two shoulders at $520 \mathrm{~cm}^{-1}$ and at $720 \mathrm{~cm}^{-1}$ represents a very important feature of the POHA structure. These peaks are related to pseudo-spinel gels and also with those of the transition aluminas that consist of tetrahedrally $\left(\mathrm{AlO}_{4}\right)$ and octahedrally $\left(\mathrm{AlO}_{6}\right)$ coordinated aluminum ${ }^{41,42}$. The $\mathrm{AlO}_{6}$ peaks can be assigned to Al-OH and Al-O stretch modes at $620 \mathrm{~cm}^{-1}$ and $520 \mathrm{~cm}^{-1}$ respectively, while the peaks at 720 $\mathrm{cm}^{-1}$ and $870 \mathrm{~cm}^{-1}$ are related to $\mathrm{AlO}_{4}$ stretching modes. The spectrum also shows peaks at 1507 and $1400 \mathrm{~cm}^{-1}$ assigned to $\mathrm{d}$-glucose that is entrapped into the as-synthesized POHA inner structure. The pseudo-spinel structure formed in aluminate solutions are metastable structures which could provide more organized trihydroxide $\left(\mathrm{Al}(\mathrm{OH})_{3}\right)$ and oxyhydroxide $(\mathrm{AlOOH})$ phases by aging and treatment in appropriate $\mathrm{pH}^{43}$.

Speciation studies showed that in conditions where $\mathrm{OH}^{-} /$ Al molar ratio values are below 4, there was a high tendency of spinel polymeric aluminate species formation, which would be made by the coalescence of monomeric, dimeric and oligomeric (like $\mathrm{Al}_{13}$ species) in solution ${ }^{41,43}$. Herein, since the experimental start condition has an $\mathrm{OH}^{-} / \mathrm{Al}$ molar ratio value of approximately 1.3 it should be an ideal or a more favorable condition to obtain a pseudo-spinel solid. The general and oversimplified formula of this polymeric structure is $\gamma-\mathrm{Al}_{2} \mathrm{O}_{3} \mathrm{xH}_{2} \mathrm{O}_{\mathrm{y}} \mathrm{OH}$ with its structure bearing the oxo and hydroxo bridges as well as edge hydroxyl subunits, therefore it was named as poly oxo-hydroxy aluminate, POHA. Figure 1(b) shows a general infrared spectrum of the $\gamma$-aluminas obtained from POHA powders after calcination. The peaks at 3464 and $1643 \mathrm{~cm}^{-1}$ are attributed to stretching and bending modes of strongly adsorbed water. The intense bands centered at 793 and $578 \mathrm{~cm}^{-1}$ are assigned to $\mathrm{AlO}_{4}$ and $\mathrm{AlO}_{6}$ coordinate aluminum that are typical of $\gamma-\mathrm{Al}_{2} \mathrm{O}_{3}{ }^{17,39,42}$. The calcination process triggered the decomposition of the d-glucose. 

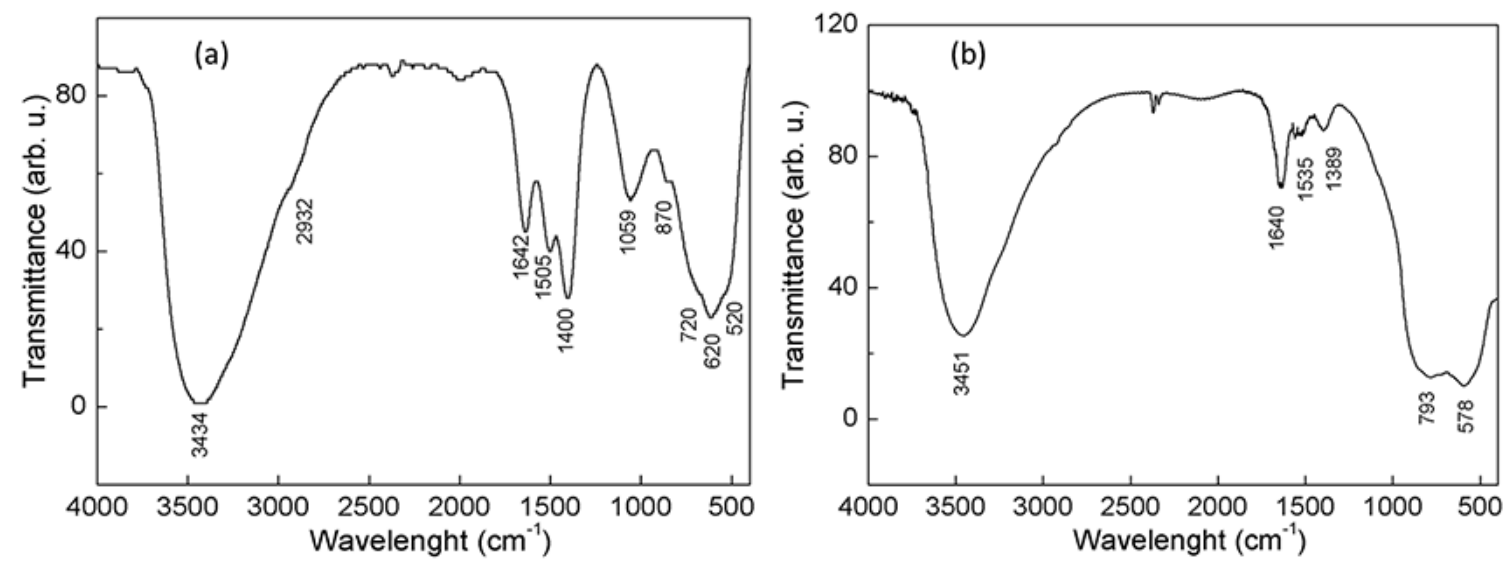

Figure 1. (a): FTIR spectrum for the as-synthesized POHA powder; (b): FTIR spectra of POHA powder calcinated at $400{ }^{\circ} \mathrm{C}$.

\subsection{X-Ray Diffraction}

The Figure 2 shows the XRD results of the as-synthesized powder (as-POHA). Figure 3 depicts the diffractogram of the samples calcined at different temperatures.

The peaks of the as-POHA powder in which are identified the crystallographic planes corresponding to potassium aluminum oxide hydrated species (PDF 190927 and 40-0703). Also, there were peaks corresponding to bayerite phase (PDF 20-0011 for $\mathrm{Al}(\mathrm{OH})_{3}$ ) and oxo hydroxy aluminum species (PDF 05-0355 for $\mathrm{AlO}(\mathrm{OH}))^{41}$. After calcination at $300{ }^{\circ} \mathrm{C}$, there are peaks corresponding to bayerite, boehmite and also some of the $\gamma-\mathrm{Al}_{2} \mathrm{O}_{3}$ phase. The arrows in fig. 3(A) indicate also the presence of some non-stoichiometric aluminum oxide hydrate (PDF 22-1119). The samples calcined at 400,700 and $900{ }^{\circ} \mathrm{C}$ showed sharp peaks at $2 \theta$ of $46.2^{\circ}$ and $67.2^{\circ}$, referring to the (400) and (440) peaks of $\gamma$-alumina, respectively (PDF 10-0425). The increase in the calcination temperature did not change the position of the peaks, thus indicating that there is no change of the structure ${ }^{9}$. The small band around $2 \theta<75-80^{\circ}$ could be referred to the vacancies of the octahedral sites that are characteristic of these spinel structures. Accordingly, in this

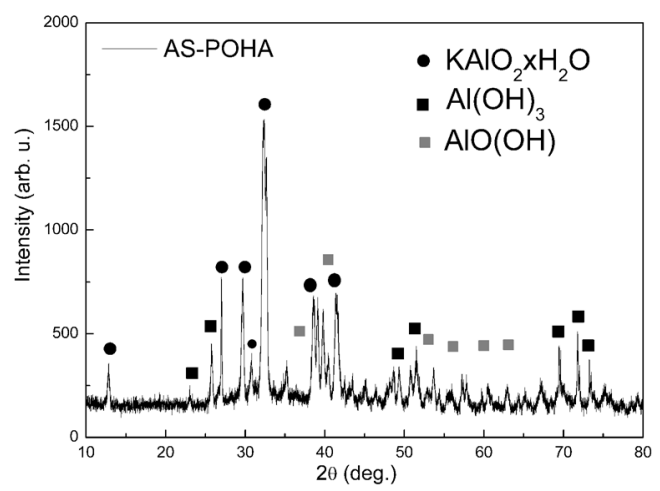

Figure 2. X-ray diffraction results for the as-synthesized POHA powder (as-POHA). work, the threshold temperature to achieve the active phase of $\gamma$-alumina was $400{ }^{\circ} \mathrm{C}$.

\subsection{Nitrogen physisorption}

The nitrogen adsorption/desorption isotherms and particle size distributions of the samples are illustrated in Figure 4. Table 1 presents the textural results from BET and BJH methods.

The samples calcined at 300,400 and $700{ }^{\circ} \mathrm{C}$ exhibited type IV isotherms with hysteresis loop between $\mathrm{H}_{1}$ and $\mathrm{H}_{2}$ type, characteristic of cylindrical or spherical pores and regular pore size distribution. Whilst the powder obtained at $900{ }^{\circ} \mathrm{C}$, which showed type II isotherm with hysteresis loop type $\mathrm{H}_{3}$, indicating the presence of disordered slit or wedge pore structures ${ }^{44}$. There is no indication of micropores since the isotherms did not present the usual "knee" at the beginning of the adsorption branch, that also can be indicated by the t-plot graph (fig. 4(c)), which has a negative intercept on the volume axis.

All samples' isotherms did not show a plateau when P/ $\mathrm{P}_{0}<1$ probably due to some macroporous presence that was not completely filled or interparticle porosity ${ }^{45}$. All samples showed a pore size distribution within the mesoporous range. As expected, the increase in temperature causes annealing of the grains that result in a decrease in the specific surface area and a broader distribution of pore sizes (especially for $\left.900{ }^{\circ} \mathrm{C}\right)^{44}$. The calcination of the POHA at $400{ }^{\circ} \mathrm{C}$ presented the best textural properties taking into account the specific surface area, pore size distribution and pore volume. The lack of micropores shows that this material could be more selective to adsorptive applications.

The high surface area mesoporous aluminas are commonly achieved through the use of structure driving agents (SDA) such as pluronic block copolymers, ionic surfactants, fatty acids, and long chain amines ${ }^{46-50}$. Recently, the use of glucose was considered to replace SDAs ${ }^{39}$. Compared with other methods of direct precipitation ${ }^{16-18,37}$, the current synthetic route brings a gain in order to produce $\gamma-\mathrm{Al}_{2} \mathrm{O}_{3}$ without the 

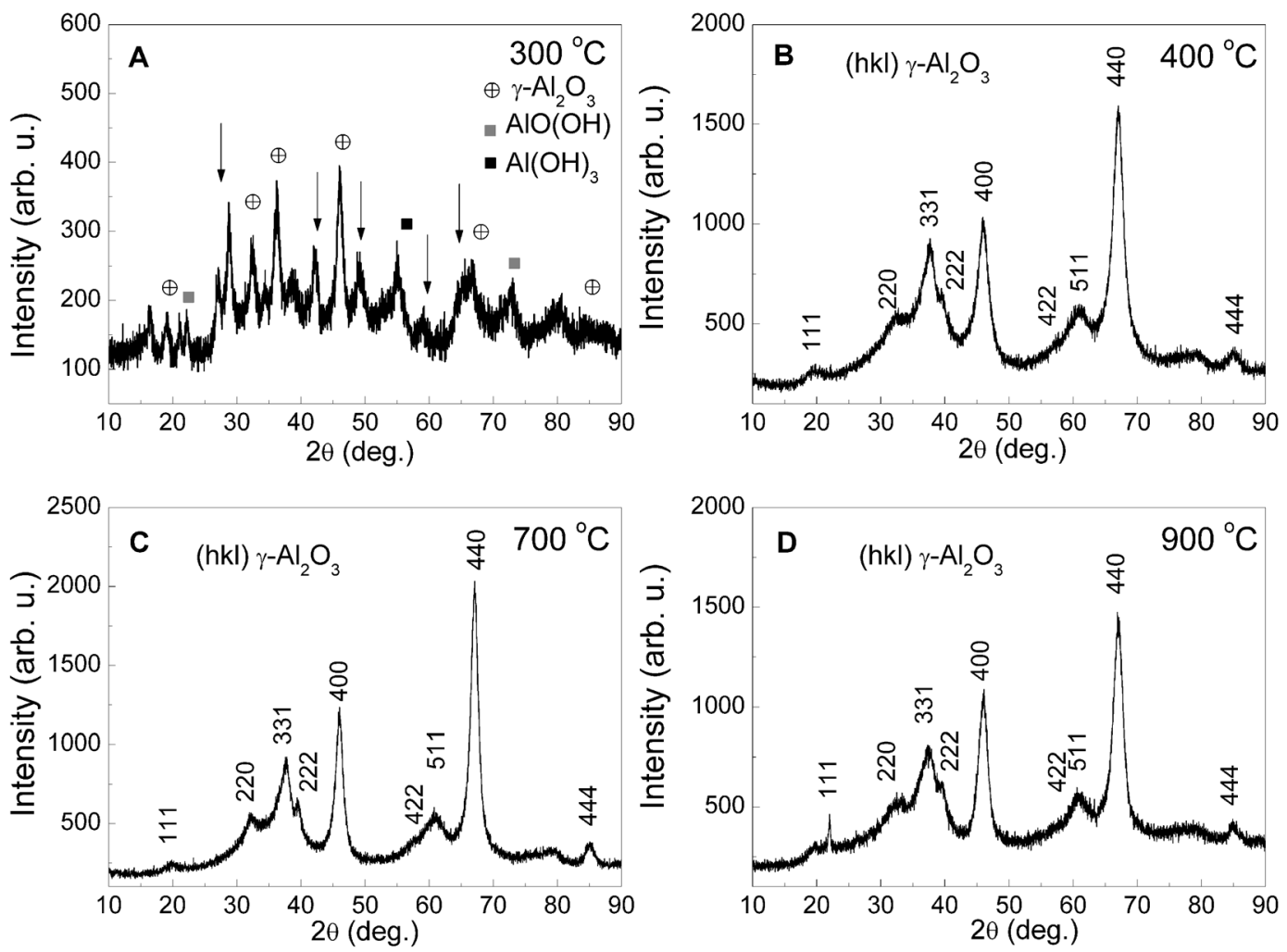

Figure 3. X-ray diffraction results for each calcination temperature: $\mathrm{A}: 300^{\circ} \mathrm{C}, \mathrm{B}: 400{ }^{\circ} \mathrm{C}, \mathrm{C}: 700{ }^{\circ} \mathrm{C}$ and $\mathrm{D}: 900{ }^{\circ} \mathrm{C}$.
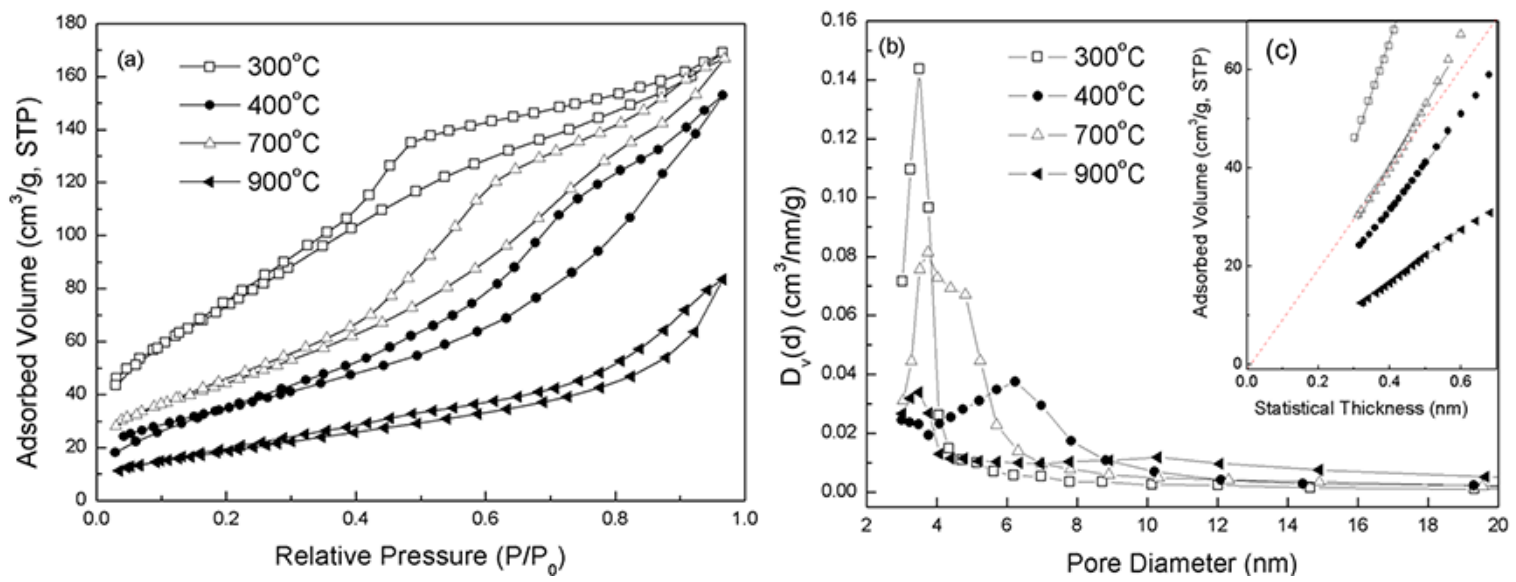

Figure 4. (a): Nitrogen isotherms of calcined POHA; (b): Pore size distribution (PSD) obtained from the adsorption branch using BJH method of calcined POHA. (c) t-plot detail revealing lack of micro-pores.

Table 1. Textural properties from nitrogen sorption measurements: specific surface area (SBET), pore volume (Vpore) and pore diameter (Dpore), for each calcination temperature of the POHA powders.

\begin{tabular}{lccc}
\hline $\mathrm{T}_{\text {calcination }}\left({ }^{\circ} \mathrm{C}\right)$ & $\mathrm{S}_{B E T}\left(\mathrm{~m}^{2} / \mathrm{g}\right)$ & $\mathrm{V}_{\text {pore }}\left(\mathrm{cm}^{3} / \mathrm{g}\right)$ & $\mathrm{D}_{\text {pore }}(\mathrm{nm})$ \\
\hline 300 & 72 & 0.13 & 3.5 \\
400 & 282 & 0.26 & 6.2 \\
700 & 166 & 0.26 & 4.0 \\
900 & 129 & 0.24 & 10.3 \\
\hline
\end{tabular}

use of SDAs leading to a large surface area gamma alumina of easy work-up. Studies are being made to expand the production scale and to further increase the surface area.

\subsection{SEM images}

The Figure 5 presents the SEM micrograph for calcined samples. In fig. 5 (a), calcination at $300{ }^{\circ} \mathrm{C}$ it is possible to 

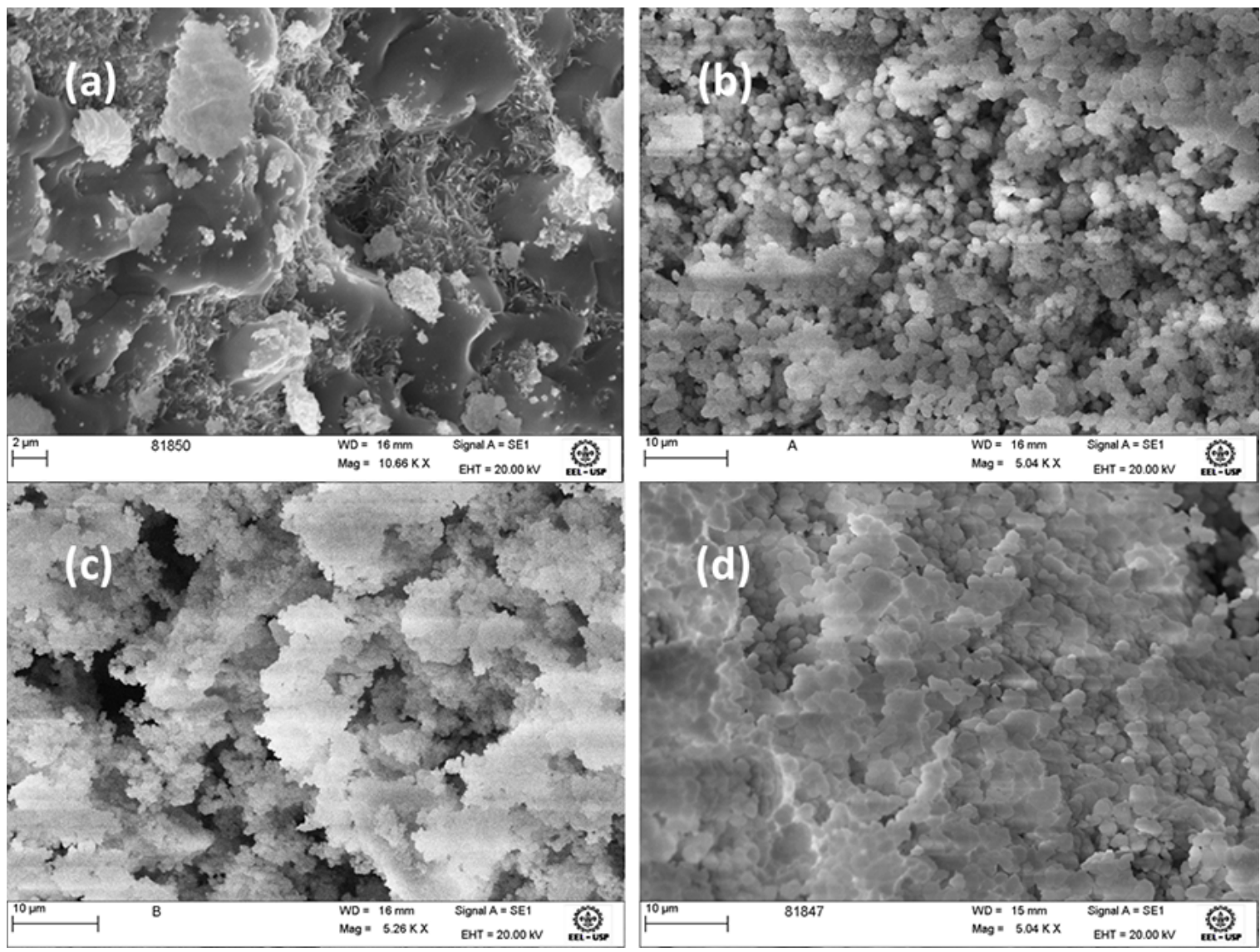

Figure 5. SEM images of the POHA powders after calcination; (a): $300^{\circ} \mathrm{C}$; (b): $400{ }^{\circ} \mathrm{C}$; (c): $700{ }^{\circ} \mathrm{C} ;(\mathrm{d}): 900{ }^{\circ} \mathrm{C}$.

notice that for this temperature there is no formation of uniform particle shape. After $400{ }^{\circ} \mathrm{C}$ calcination temperature, there are mostly spherical particles with an average diameter of $1.2 \mu \mathrm{m}$. The sample calcined at $700{ }^{\circ} \mathrm{C}$ showed more agglomeration and particles with an average diameter less than $1 \mu \mathrm{m}$ and larger aggregates. After the calcination at $900^{\circ} \mathrm{C}$, there is a densification of the system which showed particles with sizes greater than $2 \mu \mathrm{m}$.

\subsection{Synthetic Approach}

For the formation of the heterogeneous gel mixture, a high ethanol fraction (EtOH: $\mathrm{H}_{2} \mathrm{O}$ 3:1) is needed for aluminum consumption. Assays with different proportions of $\mathrm{H}_{2} \mathrm{O}-\mathrm{EtOH}(\mathrm{v}: \mathrm{v}), \mathrm{KOH}$ and d-glucose as the additive, showed different behavior. With a higher water fraction, the gel was not formed and slow precipitation of common polymorphic aluminum oxide hydrates was verified. On the other hand, with higher ethanol amount, the formation of the gel was faster and the best condition was found to be $\mathrm{H}_{2} \mathrm{O}: \mathrm{EtOH}$ 1:3 (v:v). These results point to similar pathway to those found in a previous work about ripening (dissolution-precipitation) of elemental aluminum in water-ethanol mixtures ${ }^{40}$. The aluminum consumption is dependent upon its own concentration, $\mathrm{pH}$, nature, and type of base and its counter-ion, and stability of the aluminate species in the reaction media ${ }^{51-55}$. In this process, the hard oxide shell covering the aluminum is dissolved with the metal becoming free and active to be leached ${ }^{51,56}$. Thereby, the aluminum speciation in solution reveals the presence of monomeric and oligomeric aluminates ranging from 6- to 5- and 4-coordination numbers ${ }^{57-59}$. The aluminum coordination in solution has been considered as an important feature for phase structure when organic additives or solvents are employed ${ }^{59,60}$. As mentioned above (section 1), the aluminum oxidation in $\mathrm{H}_{2} \mathrm{O}-\mathrm{EtOH}$ under sonication with a higher fraction of ethanol in aqueous mixture (i.e. $3: 1, v: v$ ) was essential to the faster precipitation of the aluminum trihydroxide (bayerite) ${ }^{40}$. As highlighted, the presence of d-glucose had a fundamental influence to achieve the POHA material since the bulk condition was the same, i.e., 1:3 water-ethanol. Since the d-glucose is capable of making hydrogen bonds, it could get in coordination with the interlayers of the initial oligomeric structures or even with the fresh aluminum cation and then favor the early aggregation of the aluminate species analytically found. These results evidence the d-glucose and ethanol are serving as targeting agents. The interference of hydroxylic compounds on the precipitation of aluminum hydroxides 
and oxides has been noted in other studies ${ }^{37,36}$. In parallel, the sonochemical route showed to be more efficient than the stirring one for the aluminum oxidation. The complete aluminum dissolution occurred in a shorter time. Once sonication gives rise to cavitation on the surface, the aluminum surface is activated faster. The sonicated reaction affording the heterogeneous gel was three times faster than the stirred reaction.

Lastly, an important point is the direct change from POHA to the $\gamma$-alumina without a previous preparation of common trihydroxide or oxyhydroxide precursors. Despite the XRD peaks assignment of bayerite and boehmite in the calcined powder at $300{ }^{\circ} \mathrm{C}$, these intermediates do not interfere with the formation of the $\gamma$-alumina phase. Thus the decisive factor appears to be the pre-aggregation of ionic aluminum oligomers with pseudo-spinel arrangements that induces the formation of the respective alumina on heating. This could be related to a Tandem process in which the common intermediates of reaction steps are not isolable.

\section{Conclusion}

The use of the as-synthesized POHA powder with d-glucose for the preparation of $\gamma$-alumina is a new method due to the decrease in the overall synthesis time and temperature. Since there was no requirement of an aging process for any aluminum hydroxide precursor, the $\gamma$-alumina phase was obtained at a lower temperature compared to other methodologies. It is very likely that the POHA changes towards the $\gamma-\mathrm{Al}_{2} \mathrm{O}_{3}$ phase at lower temperature it can be assigned as a tandem transformation. The heating treatment at $400{ }^{\circ} \mathrm{C}$ proved to attain the best textural properties, such as high specific superficial area and a narrow pore size distribution. These aluminas are used hereafter as catalyst supports for $\mathrm{ZnO}$ nanoparticles for promoting photooxidation reactions in our laboratory.

\section{Acknowledgments}

This work was supported by Fundação de Apoio à Pesquisa do Estado de São Paulo - FAPESP, grant numbers 2015/06064-6, 2013/08166-5, and for S. Brochsztain, grant number 2016/05496-2. Thanks to the funding agencies CAPES and CNPq.

\section{References}

1. Corma A. From Microporous to Mesoporous Molecular Sieve Materials and Their Use in Catalysis. Chemical Reviews. 1997;97(6):2373-2420. DOI: 10.1021/cr960406n

2. Davis ME. Ordered porous materials for emerging applications. Nature. 2002;417:813-821. DOI: 10.1038/nature00785

3. Gomez-Romero P, Sanchez C. Hybrid Materials, Functional Applications. An Introduction. In: Gomez-Romero P, Sanchez
C, eds. Functional Hybrid Materials. Weinheim: Wiley-VCH Verlag; 2005. DOI: 10.1002/3527602372.ch1

4. Bowen P, Carry C, Luxembourg D, Hofmann H. Colloidal processing and sintering of nanosized transition aluminas. Powder Technology. 2005; 157(1-3):100-107. DOI: 10.1016/j. powtec.2005.05.015

5. Chang TS, Na JH, Jung CY, Koo SM. An easy one-pot synthesis of structurally controlled aluminum hydroxide particles from an aqueous sodium aluminate solution. Journal of Ceramic Processing Research. 2009;10(6):832-839.

6. Gun'ko VM, Zarko VI, Turov VV, Oranska OI, Goncharuk OV, Nychiporuk YM, et al. Morphological and structural features of individual and composite nanooxides with alumina, silica, and titania in powders and aqueous suspensions. Powder Technology. 2009;195(3):245-258. DOI: 10.1016/j.powtec.2009.06.005

7. Keshavarz AR, Rezaei M, Yaripour F. Nanocrystalline gammaalumina: A highly active catalyst for dimethyl ether synthesis. Powder Technology. 2010;199(2):176-179. DOI: 10.1016/j. powtec.2010.01.003

8. Sivadasan AK, Selvam IP, Potty SN. Microwave assisted hydrolysis of aluminium metal and preparation of high surface area $\gamma-\mathrm{Al}_{2} \mathrm{O}_{3}$ powder. Bulletin of Materials Science. 2010;33(6):737-740. DOI: 10.1007/s12034-011-0141-1

9. Jiao WQ, Yue MB, Wang YM, He MY. Synthesis of morphologycontrolled mesoporous transition aluminas derived from the decomposition of alumina hydrates. Microporous and Mesoporous Materials. 2012;147(1):167-177. DOI: 10.1016/j. micromeso.2011.06.012

10. Naik B, Prasad VS, Ghosh NN. Preparation of ag nanoparticle loaded mesoporous $\gamma$-alumina catalyst and its catalytic activity for reduction of 4-nitrophenol. Powder Technology. 2012;232:16. DOI: $10.1016 /$ j.powtec.2012.07.052

11. Starowicz M, Starowicz P, Stypula B. Alumina-based nanoparticles obtained by anodic dissolution of AL in electrolytes with alcohol solvents. Journal of Solid State Electrochemistry. 2014;18(11):3065-3071. DOI: 10.1007/s10008-014-2447-6

12. Wawrzkiewicz M, Wisniewska M, Gun'ko VM, Zarko VI. Adsorptive removal of acid, reactive and direct dyes from aqueous solutions and wastewater using mixed silica-alumina oxide. Powder Technology. 2015;278:306-315. DOI: 10.1016/j. powtec.2015.03.035

13. Santos PS, Santos HS, Toledo SP. Standard transition aluminas. Electron microscopy studies. Materials Research. 2000;3(4):104114. DOI: $10.1590 / 81516-14392000000400003$

14. Lefèvre G, Fédoroff M. Synthesis of bayerite $\left(\beta-\mathrm{Al}(\mathrm{OH})_{3}\right)$ microrods by neutralization of aluminate ions at constant ph. Materials Letters. 2002;56(6):978-983. DOI: 10.1016/80167-577X(02)00650-X

15. Lefèvre G, Pichot V, Fédoroff M. Controlling Particle Morphology During Growth of Bayerite in Aluminate Solutions. Chemistry of Materials. 2003;15(13):2584-2592. DOI: 10.1021/cm0310059

16. Ebadzadeh T, Asadian K. Microwave-assisted synthesis of nanosized $\alpha-\mathrm{Al}_{2} \mathrm{O}_{3}$. Powder Technology. 2009;192(2):242-244. DOI: 10.1016/j.powtec.2009.01.001 
17. Parida KM, Pradhan AC, Das J, Sahu N. Synthesis and characterization of nanosized porous gamma-alumina by control precipitation method. Materials Chemistry and Physics. 2009;113(1):244-248. DOI: 10.1016/j.matchemphys.2008.07.076

18. Ghamsari MS, Mahzar ZAS, Radiman S, Hamid AMA, Khalilabad SR. Facile route for preparation of highly crystalline $\gamma-\mathrm{Al}_{2} \mathrm{O}_{3}$ nanopowder. Materials Letters. 2002;72:32-35. DOI: 10.1016/j. matlet.2011.12.040

19. Mohammadnezhad G, Akintola O, Plass W, Schacher FH, Steiniger F, Westermann M. Facile synthesis of highly thermally stable nanoporous $\gamma$-aluminas from aluminum alkoxide precursors. RSC Advances. 2015;5(61):49493-49499. DOI: 10.1039/ C5RA05883J

20. Pardo P, Montoya N, Alarcón J. Tuning the size and shape of nanoboehmites by a free-additive hydrothermal method. CrystEngComm. 2015;17(10):2091-2100. DOI: 10.1039/C4CE02094D

21. Márquez-Alvarez C, Žilková N, Pérez-Pariente J, Čejka J. Synthesis, Characterization and Catalytic Applications of Organized Mesoporous Aluminas. atalysis Reviews - Science and Engineering. 2008;50(2):222-286. DOI: 10.1080/01614940701804042

22. Kim P, Kim Y, Kim C, Kim H, Park Y, Lee JH, et al. Synthesis and Characterization of Mesoporous Alumina as a Catalyst Support for Hydrodechlorination of 1,2-Dichloropropane: Effect of Catalyst Preparation Method. Catalysis Letters. 2003;89(34):185-192. DOI: 10.1023/A:1025794127243

23. Britto JM, Rangel MC. Processos avançados de oxidação de compostos fenólicos em efluentes industriais. Química Nova. 2008;31(1):114-122.

24. Wisniewska M. Influences of polyacrylic acid adsorption and temperature on the alumina suspension stability. Powder Technology. 2010;198(2):258-266. DOI: 10.1016/j.powtec.2009.11.016

25. Karouia F, Boualleg M, Digne M, Alphonse P. Control of the textural properties of nanocrystalline boehmite $(\gamma-\mathrm{AlOOH})$ regarding its peptization ability. Powder Technology. 2013;237:602-609. DOI: $10.1016 /$ j.powtec.2012.12.054

26. Nortier P, Fourre P, Saad ABM, Saur O, Lavalley JC. Effects of crystallinity and morphology on the surface properties of alumina. Applied Catalysis. 1990;61(1):141-160. DOI: 10.1016/ S0166-9834(00)82140-5

27. Coelho ACV, Souza Santos H, Kiyohara PK, Marcos KNP, Souza Santos P. Surface area, crystal morphology and characterization of transition alumina powders from a new gibbsite precursor. Materials Research. 2007;10(2):183-189. DOI: 10.1590/8151614392007000200015

28. Amini MM, Mirzaee M. Effect of Solution Chemistry on Preparation of Boehmite by Hydrothermal Assisted Sol-Gel Processing of Aluminum Alkoxides. Journal of Sol-Gel Science and Technology. 2005;36(1):19-23. DOI: 10.1007/s10971-0054790-7

29. Wu YQ, Zhang YF, Huang XX, Guo JK. Preparation of platelike nano alpha alumina particles. Ceramics International. 2007;27(3):265-268. DOI: 10.1016/80272-8842(00)00074-2

30. Du X, Wang Y, Su X, Li J. Influences of $\mathrm{pH}$ value on the microstructure and phase transformation of aluminum hydroxide. Powder Technology. 2009;192(1):40-46.
31. Ji G, Li M, Li G, Gao G, Zou H, Gan S, et al. Hydrothermal synthesis of hierarchical micron flower-like $\gamma$-AlOOH and $\gamma-\mathrm{Al}_{2} \mathrm{O}_{3}$ superstructures from oil shale ash. Powder Technology. 2012;215-216:54-58. DOI: 10.1016/j.powtec.2011.09.005

32. Kong J, Chao B, Wang T, Yan Y. Preparation of ultrafine spherical $\mathrm{AlOOH}$ and $\mathrm{Al}_{2} \mathrm{O}_{3}$ powders by aqueous precipitation method with mixed surfactants. Powder Technology. 2012;229:7-16. DOI: $10.1016 /$ j.powtec.2012.05.024

33. Isfahani TD, Javadpour J, Khavandi A, Dinnebier R, Goodarzi M, Rezaie HR. Mechanochemical synthesis of alumina nanoparticles: Formation mechanism and phase transformation. Powder Technology. 2012;229:17-23. DOI: 10.1016/j.powtec.2012.05.034

34. Razavi-Tousi SS, Nematollahi GA, Ebadzadeh T, Szpunar JA. Modifying aluminum-water reaction to generate nano-sized aluminum hydroxide particles beside hydrogen. Powder Technology. 2013;241:166-173. DOI: 10.1016/j.powtec.2013.03.025

35. Salahudeen N, Ahmed AS, Al-Muhtaseb AH, Dauda M, Waziri SM, Jibril BY, et al. Synthesis, characterization and adsorption study of nanosized activated alumina synthesized from kaolin using novel method. Powder Technology. 2015;280:266-272. DOI: 10.1016/j.powtec.2015.04.024

36. Antunes MLP, Santos HS, Santos PS. Characterization of the aluminum hydroxide microcrystals formed in some alcohol-water solutions. Materials Chemistry and Physics. 2002;76(3):243249. DOI: $10.1016 / 80254-0584(01) 00535-1$

37. Huang B, Bartholomew CH, Woodfield BF. Facile structurecontrolled synthesis of mesoporous $\gamma$-alumina: Effects of alcohols in precursor formation and calcination. Microporous and Mesoporous Materials. 2013;177:37-46. DOI: 10.1016/j. micromeso.2013.04.013

38. Zhang Y, Zheng S, Xu DH, Xu H,Wang S, Zhang Y. Improved precipitation of gibbsite from sodium aluminate solution by adding methanol. Hydrometallurgy. 2009;98:38-44. DOI: 10.1016/j.hydromet.2009.03.014

39. Obrenović Z, Milanović M, Djenadić RR, Stijepović I, Giannakopoulos KP, Perušić M, et al. The effect of glucose on the formation of the nanocrystalline transition alumina phases. Ceramics International. 2011;37(8):3253-3263. DOI: 10.1016/j. ceramint.2011.05.120

40. Triboni ER, da Silva MFP, Finco AT, Rodrigues MA, Demets GJF, Dyszy FH, et al. Synthesis and properties of new paramagnetic hybrid bayerite from $\mathrm{Al}^{(0)} /$ naphthalene dianhydride reaction. Materials Research. 2010;13(4):105-111. DOI: 10.1590/ S1516-14392010000400013

41. Bradley SM, Hanna JV. ${ }^{27} \mathrm{Al}$ and ${ }^{23} \mathrm{Na}$ MAS NMR and Powder X-ray Diffraction Studies of Sodium Aluminate Speciation and the Mechanistics of Aluminum Hydroxide Precipitation upon Acid Hydrolysis. Journal of the American Chemical Society. 1994;116(17):7771-7783. DOI: 10.1021/ja00096a038

42. Shen L, Hu C, Sakka Y, Huang Q. Study of phase transformation behaviour of alumina through precipitation method. Journal of Physics D: Applied Physics. 2012;45(21):215302. DOI: 10.1088/0022-3727/45/21/215302 
43. Bradley SM, Kydd RA, Howe RF. The Structure of Al Gels Formed through the Base Hydrolysis of $\mathrm{Al}^{3+}$ Aqueous Solutions. Journal of Colloid and Interface Science. 1993;159(2):405-412. DOI: $10.1006 /$ jcis. 1993.1340

44. Tommes M. Physical Adsorption Characterization of Nanoporous Materials. Chemie Ingenieur Technik. 2010;82(7):1059-1073. DOI: $10.1002 /$ cite. 201000064

45. Liu B, Baker RT. Factors affecting the preparation of ordered mesoporous $\mathrm{ZrO}_{2}$ using the replica method. Journal of Materials Chemistry. 2008;18(43):5200-5207. DOI: 10.1039/B807620K

46. Niesz K, Yang P, Somorjai AG. Sol-gel synthesis of ordered mesoporous alumina. Chemical Communications. 2005;(15):19861987. DOI: $10.1039 / \mathrm{b} 419249 \mathrm{~d}$

47. Bagshaw SA, Prouzet E, Pinnavaia TJ. Templating of mesoporous molecular sieves by nonionic polyethylene oxide surfactants. Science. 1995;269(5228):1242-1244. DOI: 10.1126/ science.269.5228.1242

48. Liu C, Liu Y, Ma Q, He H. Mesoporous transition alumina with uniform pore structure synthesized by alumisol spray pyrolysis. Chemical Engineering Journal. 2010;163(1-2):133-142. DOI: 10.1016/j.cej.2010.07.046

49. Zhang Z, Pinnavaia TJ. Mesoporous $\gamma$-Alumina Formed Through the Surfactant-Mediated Scaffolding of Peptized Pseudoboehmite Nanoparticles. Langmuir. 2010;26(12):10063-10067. DOI: 10.1021/la101266d

50. Zhang Z, Hicks RW, Pauly TR, Pinnavaia TJ. Mesostructured Forms of $\gamma-\mathrm{Al}_{2} \mathrm{O}_{3}$. Journal of the American Chemical Society. 2002;124(8):1592-1593. DOI: 10.1021/ja016974o
51. Pourbaix M. Atlas of electrochemic equilibria in aqueous solutions. Oxford: Pergamon Press; 1966.

52. Uhlig HH, Revie RW. Corrosion and Corrosion Control: an introduction to corrosion science and engineering. $3^{\text {rd }} \mathrm{ed}$. Weinheim: Wiley-VCH; 1985.

53. Adhikari S, Lee J, Hebert KR. Formation of Aluminum Hydride during Alkaline Dissolution of Aluminum. Journal of the Electrochemical Society. 2008;155(1):C16-C21. DOI: $10.1149 / 1.2800770$

54. Orvig C. The aqueous coordination chemistry of aluminum. ChemInform 1993;24:85-120.

55. Sidrak YL. Dynamic Simulation Approach to Digester Ratio Control in Alumina Production. Industrial \& Engineering Chemical Research. 1998;37(4):1404-1409. DOI: 10.1021/ ie 9704206

56. Landsberg JP, McDonald B, Watt F. Absence of aluminium in neuritic plaque cores in alzheimer's disease. Nature. 1992;360(6399):65-68. DOI: 10.1038/360065a0

57. Swaddle TW, Salermo J, Tregloan PA. Aqueous aluminates, silicates, and aluminosiiicates. Chemical Society Reviews. 1994;23(5):319-325. DOI: 10.1039/CS9942300319

58. Sipos $\mathrm{P}$. The structure of $\mathrm{Al}_{\text {(iii) }}$ in strongly alkaline aluminate solutions - A review. Journal of Molecular Liquids. 2009;46(12):1-14. DOI: 10.1016/j.molliq.2009.01.015

59. Lahodny-Šarc O, Dragčević Z, Došen-Šver D. The Influence of the Activity of Water on the Phase Composition of Aluminum Hydroxides Formed by Reaction of Amalgamated Aluminum with Water. Clays and Clay Minerals. 1978;26(2):153-159. DOI: 10.1346/CCMN.1978.0260211

60. Porciúncula CB, Marcilio NR, Tessaro IC, Gerchmann M. Production of hydrogen in the reaction between aluminum and water in the presence of $\mathrm{NaOH}$ and KOH. Brazilian Journal of Chemical Engineering. 2012;29(2):337-348. DOI: 10.1590/ S0104-66322012000200014 